may have a common dynamic origin which, perhaps, is a super-supernova explosion as proposed by Rickard ${ }^{6}$.

V. R. VENUGOPAI

Dominion Radio Astrophysical Observatory,

Penticton, BC,

Canada.

Receired June 15, 1970.

Vaucouleurs, G. de, and Peters, W. L., Nature, 223, 938 (1969).

2 Kerr, F. J., and Sullivan III, W. T., Astrophys. J., 158, 115 (1969), 3cCutcheon, W. H., Shuter, W. L. H., and Venugopal, V. R., J. Roy.
Astron. Soc. Canada, 63, 312 (1969).

+ Verschuur, G. L., Astrophys. J., 156, 771 (1969)

'Dieter, N. FI., Pub. Astron. Šoc. Pacific, 81, 186 (1969).

${ }^{6}$ Rickard. J. J., Astrophys. J., 152, 1019 (1968).

\section{Penetration of Solar Particles to lonospheric Heights at Low Latitudes}

Ganguly and Rao recently presented evidence for the possibility of the penetration of high energy solar particles to ionospheric heights at the equator ${ }^{1}$. Their letter, based on ionospheric absorption data obtained at Caleutta (geomagnetic latitude $12^{\circ} 15^{\prime} \mathrm{N}$ ), together with optical observations of solar flares and tabulated proton flux data, is very interesting in the light of extensive work recently on the penetration of solar particles to low magnetospheric $L$-values $\left(L \sim 4-7 R_{\mathrm{E}}\right)$ at the equator ${ }^{2-7}$. Because the observations of Ganguly and Rao would have a profound and far-reaching impact on current ideas of the mechanisms for the access of such solar particles to the geomagnetic equator ${ }^{2-4,6}$, the ionospheric and solar evidence presented by the Calcutta group has been examined carcfully. We conclude that there is little basis for thoir contention that solar particles can penetrate directly to low altitudes and thus influence ionospheric absorption at the equator.

Ganguly and Rao present perhaps their most conclusive evidence in their Fig. 2. They plot, as a function of time, the night-time absorption (for $4.7 \mathrm{MHz}$ ) and the "proton flux $(E>60 \mathrm{MeV})$ measured by Explorer 33" for the period 1400 VT August 1 to 0300 UT August 2, 1967. Proton data $(E \sim 60 \mathrm{MeV})$ measured by the Bell Laboratories instrument on ATS- 1 at the equator $\left(150^{\circ} \mathrm{W}\right.$ gcographic longitude) at synchronous altitude were examined for evidence of a solar particle enhancement occurring around the time reported in ref. 1. No evidence for such an enhancement was found.

The $E>60 \mathrm{MeV}$ proton data from the solar proton monitoring experiment on Explorer 34, published routinely in the ESSA bulletin Solar Geophysical Data ${ }^{8}$, were examined for a proton enhancement as presented by the Calcutta group. During the time period discussed by Ganguly and Rao, Explorer 34 was at perigee and thus measuring the electron radiation belts by electron pile-up in the proton chamnels ${ }^{9}$. It was found that the $E>60 \mathrm{MeV}$ data presented by Ganguly and Rao were equal to the fluxes reported by the Explorer 34 solar proton monitoring experiment during its perigee-pass through the radiation belts. Hence we conclude with respect to the "correlation" presented in Fig. 2 of the letter by Ganguly and Rao that: (1) ATS-1 data give no evidence of a solar proton enhancement at high altitudes at the equator; (2) Ganguly and Rao were evidently using Explorer 34 and not Fxplorer 33 data in their comparison; (3) the data they plotted were the perigee-pass data when the satellite detector was measuring the radiation belts.

We have examined the optical flare data and the solar proton data from ATS-1 and Explorer 34 during the three periods of anomalous absorption presented in Fig. 1 of Ganguly and Rao. The optical flare data which we used were those in the master list of flares and subflares compiled by World Data Center A and published in Solar Geophysical Data ${ }^{10}$. Although not stated explicitly in their caption to Fig. 1, Rao informs us that the data wero plotted in Indian Standard Time (IST $=$ UT $+5 \cdot 5 \mathrm{~h}$ ).

The flare that occurred between 0337 and 0352 UT, February 11, 1968, was classified as $-\mathrm{N}$ (ref. 10). The flare that occurred between 0416 and 0439 UT, February 14, 1968, was classified as $1 \mathrm{~B}$ (ref. 10). No evidence of high energy solar protons was observed at synchronotis altitude on ATS-I at the time of either of the two absorption events which Ganguly and Rao associated with these flares. Explorer 34, located in the magnetotail, also measured no high energy solar protons. A small flux of low energy ( $\leq \mathbf{5} \mathrm{MeV}$ ) solar protons was observed on both ATS-1 and Explorer 34 throughout February 14. The flare that Ganguly and Rao reported as occurring between 0820-0840 UT, February 7, 1968, was classified as IF in the list of "Small or Unconfirmed" flares" ${ }^{10}$. No solar protons in any energy range were observed on either satellite during this day.

We conclude with respect to the three February 1968 flare events in Fig. 1 of Ganguly and Rao that the solar proton data do not support the authors' contentions that high energy protons contribute to low altitude equatorial absorption at Calcutta. We further note that the three February 1968 flares used by Ganguly and Rao were smaller than the flares that generally produce high energy proton fluxes at the Earth.

In summary, we find the evidence for correlation of proton events with low altitude equatorial absorption to be invalid, and find the supporting flare data to be unconvincing and unsupported by spacecraft measurements.

We thank Miss E. Ruth Hedemann of the MeMathHulbert Observatory, University of Michigan, for com. ments on optical flare reporting and publication, and Dr M. Rao for comments on the first draft of this letter.

Bell Telephone Laboratories,

L. J. LANZEROTT'

Murray Hill, New Jersey 07974

Bell Telephone Laboratories,

\section{T. E. GraEdeI} Whippany, New Jersey 07981.

Received June 4, 1970.

${ }^{1}$ Ganguly, S., and Rao, M., Nature, 225, 169 (1970).

${ }^{2}$ Filius, R. W., Ann. Geophys., 24, 821 (1968).

${ }^{3}$ Lanzerotti, L. J., Phys. Rev. Lett., 21, 929 (1968).

1 Paulikas, G. A., and Blake, J. B., J. Geophys. Res., 74, 2161 (1969).

"Paulikas, G. A., and Blake, J. B., J. Geophys. Res., 75, 734 (1970).

- Lanzerotti, L. J., Proc. Third ESRO Symp. (G. Reidel Pub. Co., 1970).

Lanzerotti, L. J., Montgomery, M. D., and Singer, S., J. Geophys. Res.. r5 (1970).

s Solar Geophysical Data, IER-FB-282, 147 (US Dept Commerce. 1968).

Solar Geophysical Data, IER-FB-294 (Supp.), 64 (Us Dept Commerce, 1969).

10 Solar Geophysical Data, IER-FB-288, 103 (US Dept Commerce, 1968).

\section{Transform Faulting in the Thai Peninsula}

RECENT mapping by a joint UK/Thai team of geologists ${ }^{1}$, operating under the Colombo Plan, has shown that the angular elbow-like feature in the Phuket area of peninsular Thailand projecting into the Andaman Sea is the physiographic expression of two major transcurrent faults with a total sinistral displacement of at least $200 \mathrm{~km}$.

A zone of rich tin-bearing granites stretching up the Malay Peninsula into Thailand as far as Surat Thani has been offset by both faults. Across the largest of these, the Khlong Marui Fault, the belt has been displaced a distance of at least $150 \mathrm{~km}$ to the south-west to Phuket Island, whence it continues up the western part of the Thai Peninsula to Ranong (Figs. 1 and 2c). Across the Ranong Fault the tin-bearing zone has again been displaced at least $20 \mathrm{~km}$ to the south-west and the offset northern part of the zone passes through the islands of 